\title{
REFLEXÕES SOBRE ALTERNATIVAS PARA A ENTRADA DA CRIANÇA NA ESCRITA
}

RESUMO: Neste artigo, a intenção é refletir sobre alternativas para a entrada da criança na escrita. Neste sentido, o objetivo principal é enfatizar a importância da experiência emocional da criança, diante do livro de história, e a relação especial que se estabelece entre a criança e 0 adulto, na medida em que se abre um espaço para percepções, conhecimentos e emoções na fase inicial da escrita. Os resultados são apresentados e discutidos em exemplos extraídos de pesquisa realizada.

PALAVRAS-CHAVE: Reflexões; Alternativas; Entrada; Criança; Escrita.

\section{ALTERNATIVES FOR CHILDREN'S INTRODUCTION TO WRITING}

ABSTRACT: The alternatives for children's introduction to writing are discussed. The article underscores children's emotional experience before the story book. Special relationships are established between children and adults as new spaces for perception, knowledge and emotions are opened within the initial writing phases. Results are forwarded and discussed from examples given during research.

KEYWORDS: Reflections; Alternatives; Introduction; Children; Writing.

\section{INTRODUÇÃo}

A escolha do tema, neste trabalho, não implica apenas a aprendizagem da escrita de letras, palavras e orações. Nem tampouco envolve somente uma relação da criança com a escrita. Ela vai além, na medida em que traz em si uma proposta de construção do sentido, levando em conta a interação com o outro. Neste sentido, ela pressupõe um desejo e o envolvimento de um interlocutor, geralmente, um adulto letrado, que escuta as proposições da criança, e empresta sua própria colaboração discursiva.

Estamos admitindo que a escuta da leitura de história, quando a criança ainda não sabe ler, constitui um recurso importante de observação para a entrada da criança na escrita. Por um lado, porque the permite 0 acesso a diversos tipos de materiais escritos e, por outro lado, porque possibilita "0 contato com práticas culturais mediadas pela escrita”. 0 exercício desta prática de leitura coloca as crianças no papel de "leitoras", que podem relacionar a linguagem com os textos e os gêneros. Por isso, cabe ao professor, além de ler para as crianças, organizar situações, em que as crianças precisam descobrir o sentido do texto apoiando-se nas figuras que 0 acompanham, na diagramação, em seus conhecimentos prévios sobre 0 assunto, criando um ambiente agradável e convidativo à escrita atenta, permitindo que elas olhem 0 texto e as ilustrações enquanto a história é lida. Portanto, a leitura de histórias é o momento em que a criança pode conhecer a forma de viver, pensar, costumes e comportamentos de outras culturas situadas em outros tempos e lugares.

Prosseguindo, o processo de entrada da criança na escrita constitui um desafio de abordagem, uma vez que coincide com um momento especial de um processo particular, em que a criança reconstrói a história de sua relação com a linguagem, ao mesmo

\footnotetext{
Doutorado em Linguística Geral/Sorbonne, Paris, França. Livre-Docente em Psicolinguística, Departamento de Linguística na Universidade de São Paulo (USP), Brasil. E-mail: Ieliaerbolato@hotmail.com
} 
tempo em que passa a refletir sobre ela. Por isso, estas reflexões justificam, em linhas gerais, nosso interesse em retomar e interpretar o trabalho da criança, na etapa inicial de entrada na escrita, e nos convidam também a buscar ajuda, que vai da psicologia, passando pela linguística, psicolinguística, psicanálise, etnografia da comunicação.

A escolha do título do artigo e a intenção de enfatizar a importância da experiência emocional da criança (diante do livro de história) justificam nossa intenção de destacar a relação toda especial que se estabelece, durante a leitura de um livro, entre a criança e 0 adulto, na medida em que acaba abrindo um espaço, para o registro de percepções, conhecimentos e emoções, na fase inicial da escrita.

Partindo destes pressupostos iniciais, nosso objetivo principal é descrever e explicar as estratégias utilizadas, por ocasião das trocas verbais (adulto/criança), nas diferentes atividades de narração, durante 0 processo de figuração, e situações propostas de escrita. Não perdendo de vista o modelo bakhtiniano, e como objetivos específicos, postulamos que 0 adulto ocupa, em relação ao discurso que se constrói, três posições principais: uma primeira posição, que incita a criança a falar; uma segunda posição, que preenche a ausência eventual de discurso da criança; e, finalmente, uma terceira posição, que aparece como reação à sua produção verbal.

Na abordagem destas três posições, 0 interesse é também reconhecer a natureza indissociável e a complexa relação entre oralidade e escrita. Para isso, admitimos a necessidade de levar em conta alguns pressupostos teóricos (ideias) e práticas (atividades). Com base na intensidade de interesse pelo assunto, a seguir, propomos algumas questões:

A) 0 que uma criança deve saber para começar a ler/escrever? 0 que a leva a ter interesse pela escrita?

B) É possível falar em estilo individual nas fases iniciais da escrita? Sendo possível, como se caracteriza este estilo?

C) Até que ponto o "peso" do componente literário, ou do gênero narrativo, tende a atenuar o contexto, no qual a criança aprende a ler e escrever na escola?

As respostas a estas questões consideram alguns pressupostos teóricos (ideias) e práticas (atividades), que norteiam a aprendizagem da leitura e da escrita, na escola, e favorecem o conhecimento da natureza indissociável entre oralidade e escrita.

Sobre as práticas de leitura e de escrita, estamos entendendo que se trata de estratégias das quais o(a) professor(a) pode lançar mão, para enriquecer as atividades de leitura, ou de escrita, a serem realizadas. A seguir, destacamos a contribuição dos seguintes autores sobre 0 tema a aquisição da escrita:

1) Conforme Abaurre, Fiad e Mayrink-Sabinson (1997, p. 22), "a aquisição da escrita é um momento particular de um processo mais geral de aquisição da linguagem. 0 sujeito, em contato com a representação escrita da língua, ele reconstrói a história de sua relação com a linguagem". 0 sujeito, ao contemplar a forma escrita da língua, passa a refletir sobre a própria linguagem. Ainda de acordo com as autoras, é assim que "a escrita é considerada o espaço importantíssimo de manifestação da singularidade dos sujeitos" (1997, p. 23).

2) Para Chauveau (1993), ler é ao mesmo tempo descodificar, compreender e controlar esta atividade. Compreender é a compreensão de um texto escrito. 0 domínio do saber ler implica que a criança tenha compreendido a natureza e as funções da escritura, e os aspectos essenciais da tarefa a 
realizar e a maneira de tornar-se leitor. É 0 aprendiz leitor que pode nos mostrar o que é a aprendizagem da leitura.

3) Para, Weiss (1985, apud FIJALKOW, 1996), as diversas trocas orais estabelecidas entre crianças e pais, por ocasião da leitura \{em voz alta] de livros, permitem à criança perceber que as histórias lidas existem em livros onde figuram grafismos diversos, imagens e texto [...].

4) Kato, M. A. (1997) apresenta uma retrospectiva dos trabalhos relevantes à compreensão do processo de alfabetização, com base em seus aspectos individuais e sociais, conforme as perspectivas psicolinguística e sociolinguística. Nesta perspectiva teórica, a autora leva em conta 0 que é relevante nas concepções das crianças sobre a escrita.

5) Massenet, J. e Jeanjean, M. E. (1993) descrevem os resultados obtidos em uma pesquisa com crianças da pré-escola. Conforme os autores, na atividade da "escrita acompanhada", a criança parece confundir "escrever" e "desenhar", uma vez que começa a conhecer a escrita. A atividade da "escrita acompanhada" parece favorecer uma reflexão sobre seu funcionamento, tanto no nível das situações, em que ela tem um papel, como sobre a própria escrita.

6) Rego, R. (1990) propõe a utilização da literatura infantil, como uma das formas possíveis e viáveis de articulação das atividades, e de constituição da interdiscursividade, no momento da entrada da criança na escrita, criando, então. novas condições e possibilidades de trocas de saberes do interesse das crianças.

7) Melo, L.E. (2003) retoma, inicialmente, algumas crenças defendidas sobre a aquisição da escrita, na década de 70, com 0 objetivo de pensar e redimensionar, a partir da perspectiva bakhtiniana, e da abordagem interacionista, a visão de escrita, do ponto de vista de interação e interlocução, em diferentes atividades, como interação entre livro-criança-adulto, recontar histórias, narração e narrativa, desenhar. 0 objetivo é mostrar a necessidade de reconhecer a natureza indissociável de aquisição da escrita e a complexa relação entre oralidade e escrita.

\section{METODOLOGIA}

A pesquisa foi realizada em sessões interativas com cinco crianças na faixa etária de cinco anos de idade. As crianças selecionadas (03 do sexo masculino e 02 do sexo feminino) frequentavam a pré-escola na cidade de São Paulo/SP, e não apresentavam comprometimento fonoaudiológico. Os dados coletados foram transcritos de acordo com as normas do projeto NURC/SP (1990), utilizadas por Preti e Urbano (1990).

No processo de elaboração e produção compartilhada, foram propostas duas atividades: (a) situação de leitura-escrita (com 0 adulto e a criança), a partir da visualização e da leitura do texto "A pedra no caminho" (Esconde-Esconde, Eva Furnari, 4. ed., 1988, p. 14-15); (b) pedido para a criança contar, ou inventar, uma história. Como alternativa de constituição da interdiscursividade, a "literatura infantil", é levada em conta, em razão de sua dimensão lúdica e estética.

Com 0 propósito de buscar 0 engajamento das crianças nas atividades de figuração e escrita, foi adotado um comportamento interativo (adultocriança).

Paralelamente, nas diferentes situações de coleta dos dados, a variação semiológica das condutas verbais foi também levada em consideração, sob dois pontos de vista: (a) a relação da mensagem com 0 objeto ao qual se refere; (b) relação com a mensagem 
do "outro", adulto ou criança.

Estes pontos de vista sinalizam, por um lado, a necessidade de reconhecer a natureza indissociável da aquisição da escrita, característica da criança, e a complexa relação entre oralidade e escrita. Por outro lado, as escolhas mediadas pelo nosso olhar e os aspectos observados, a partir dos dados coletados, constituem um convite para uma reflexão sobre a questão da singularidade, no período que antecede a escolarização:

(a) (Narrativa de uma história a partir da visualização de cinco imagens de "A pedra no caminho", do livro (Esconde-Esconde, Eva Furnari, 4. ed., 1988: 4-5).

\section{ALGUNS FIOS CONDUTORES DA ANÁLISE E INTERPRETAÇÂO DOS RESULTADOS}

Neste trabalho, nossa atenção está voltada para o momento em que a criança busca estabelecer uma distinção entre 0 icônico e 0 não icônico, ou seja, entre desenhar e escrever, entre os resultados destas duas ações.

Estamos admitindo também que a produção escrita de uma criança pode ser feita sob dois pontos de vista diferentes: um ponto de vista, referente aos aspectos figurativos da escrita, e o outro ponto de vista referente aos aspectos construtivos da escrita. Dando continuidade a estas reflexões, destacamos dois aspectos pertinentes que deveriam ser levados em conta: (a) o triângulo livro-criança-adulto; (b) as atividades de narração e as narrativas:

(a) Sobre o triângulo livro-criança-adulto... Para o psicanalista infantil Diatkine (1986), se 0 interesse que as crianças manifestam, por um lado, quando colocamos ao seu alcance os livros , é sempre surpreendente, sobretudo, se as crianças não sabem ler, observamos também, por outro lado, que a relação da criança com os livros evidencia a autonomia de sua capacidade de sonhar.

(b) Sobre as atividades de narração e as narrativas... A narração é a maneira clássica

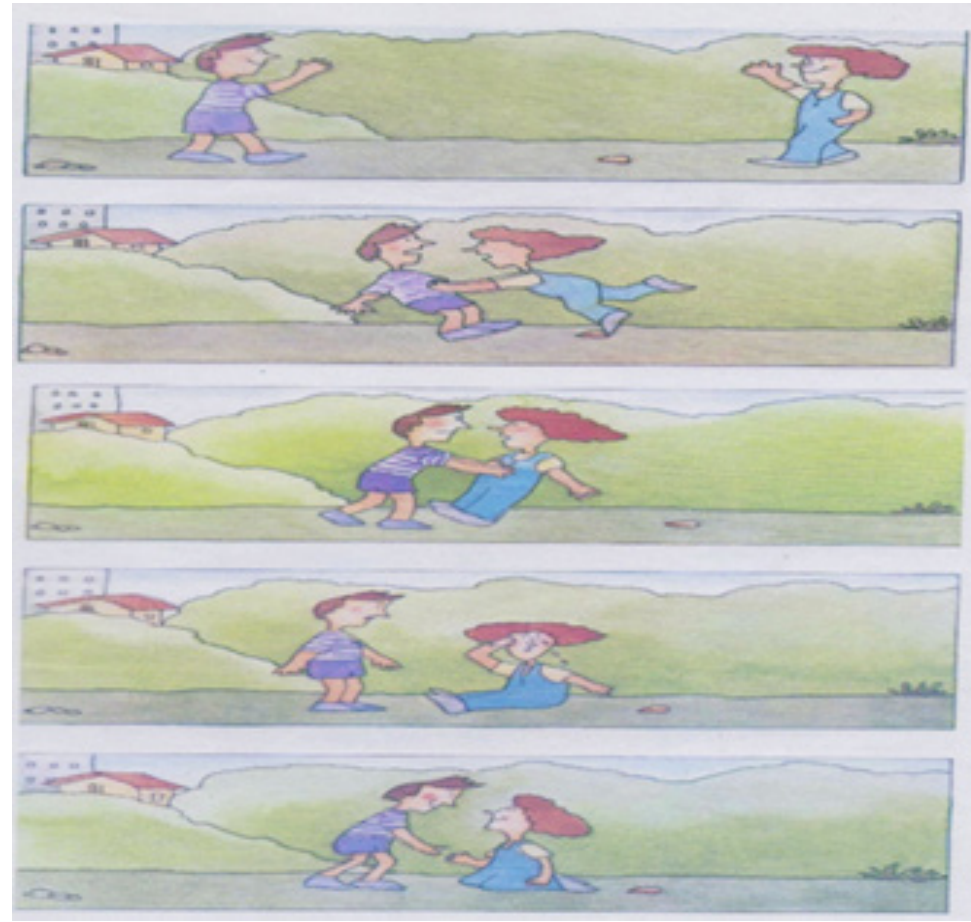

Figura 1. A pedra no caminho 
de 0 adulto ler histórias para a criança que, geralmente, escuta, olhando as imagens do texto. Esta estratégia caracteriza-se por uma centralização da atenção no próprio texto (seja lido ou contado), e por certa interação, uma vez que 0 adulto 0 relê, ou repete, sempre do mesmo modo. A narrativa aparece, por um lado, como um lugar de encontro das dimensões afetivas e cognitivas. Por outro lado, as narrativas se constroem numa certa coerência dialógica, em função dos saberes e das expectativas e encontram seu sentido, ao cumprir certo efeito no ouvinte-leitor (Labov, 1978). Enfim: as narrativas aparecem como "a cultura modela a mente" (Bruner, 1991), pois fornecem ao sujeito importantes elementos de elaboração de seu "conhecimento do mundo".

\section{Exemplo 1}

Situação de leitura-escrita entre 0 adulto e as crianças, a partir da visualização e da leitura de cinco imagens do texto "A pedra no caminho", EscondeEsconde, Eva Furnari, 4. ed. 1988, p. 14-15.

A: muito bem e agora vocês [...] se lembram desse livro não foi? outro dia vocês leram

An: Esconde-Esconde (Eva Furnari)

$\mathrm{H}$ : ah [...] eu li

PR: eu li

A: vamos fazê outra história

$H:$ ah [...] eu já vi esse daí

An: A pedra no caminho (Eva Furnari)

$C$ : olha a pedra no caminho

A: vamos contá quem é que que conta a história?

An: eu

PR: eu quero

$\mathrm{H}$ : eu quero

C: eu quero primeiro
$\mathrm{H}$ : eu que leio... onde que eu fui li mesmo?

C: a pedra tava no meio?

A: (risos)

C: a pedra tava no meio aí depois a menina foi falou assim foi falá um negócio aí depois ela ela caiu derrubô o menino e a menina...

A: por que ela caiu Camila?

C: aí depois ela chorô aí o menino chorô pra ela

A: mas [...] por que ela chorô?

PR: aí depois ela foi embora e morreu

C: ah [...] por que tava doendo é o pé dela aí depois...

A: 0 pé dela tava doendo? [...] mas por que ficou doendo o pé?

C: por causa que a pedra era muito dura

A: ah [...] ela bateu o pé na pedra

*Comentário: aqui, observa-se uma aparente dificuldade momentânea por parte do sujeito para distinguir "o que é para ler" em um livro, ao mesmo tempo em que o papel facilitador do adulto conduz ou inaugura novos momentos de interlocução pela própria incompletude, isto é, pelo que cada criança disse ou deixou de dizer na elaboração de uma história encadeada, a partir das figuras.

\section{Exemplo 2}

Pedido para contar, ou inventar, uma história.

A: eu vou pedir pra você contar uma história [...] conta pra mim inventa uma história e me conta

PR: não sei lê nenhuma história

A: mas olha você deve ter ouvido Muitas histórias

PR: já ouVl

A: enTÃo conta uma pra mim

PR: mas meu pai contô uma da formiguinha

A: ah[...] eu não conheço como é que é? [...] como é que é essa história? 
PR: que ela queria passá pelo rio mas não conseguiu daí o elefante falou pra ela i subí nas costa o elefante subiu subiu e deixou ela no outro lado do rio e depois ela foi pra casa

A: não diga e ele não quis mais voltar pro outro lado do rio? ficou pra sempre lá do outro lado? [...] mais alguma coisa nessa história?

*Comentário: neste exemplo, a criança mostra que sabe fazer a distinção entre "contar" e "ler". Com a ajuda do adulto, propõe-se, então, a (re)contar a história.

\section{CONSIDERAÇÕES FINAIS}

Sem a pretensão de ter chegado a conclusões sobre 0 tema, 0 trabalho em questão tem 0 objetivo de contribuir de alguma forma para repensar alguns pontos na discussão sobre 0 processo de aquisição da língua escrita. Um papel que, para nós, pode ser visto como de 'intérprete', uma vez que introduz a criança pequena no movimento linguístico-discursivo da escrita:

1. Conforme Scarpa (1987: 118-128), pudemos identificar, nesta pesquisa, uma continuidade processual entre a aquisição e 0 desenvolvimento da linguagem oral, sem perder de vista a aprendizagem da escrita.

2. A análise dos fragmentos selecionados nos permitiu verificar, também, o que a criança diz da escrita, quando ela se confronta ativamente, com a situação, e 0 que ela faz para tentar ler-escrever, antes de chegar a fazê-lo, e nos possibilitou reconstituir o que a criança pensa.

3. Além disso, o que a criança diz nos esclarece também sobre o que ela faz, quando procura interpretar a escrita que encontra ou a escrita que produz. Porque, antes mesmo de entrar na escola, a criança mantém relações complexas, ou despercebidas, com a escrita que está presente em seu ambiente, mas que a escola tende a fazer tabula rasa.

4. Estamos admitindo, portanto, que "a entrada da criança na escrita", situa-se, naquele momento que pressupõe a passagem das crianças de uma concepção figurada da escrita a uma concepção linguística da escrita. Inclusive, esta passagem vai nos permitir observar também a emergência de traços individuais de estilo.

Concluindo, e com o olhar voltado para a aquisição de linguagem, verificamos que a questão fundamental não seria mais como ensinar a ler para a criança, mas o que acontece, quando ela aprende a ler.

\section{REFERÊNCIAS}

ABAURRE, M. B. M.; FIAD, R. S.; MYRINK-SABINSON, M. L. T. Cenas de aquisição da escrita: 0 sujeito e 0 trabalho com o texto. Campinas, SP: Associação de Leitura do Brasil (ALB); Mercado de Letras, 1997.

BAKHTIN, M. (V.N. Volskinov). Estética da criação verbal. Tradução de Maria Ermantina Galvão Gomes Pereira. São Paulo: Martins Fontes, 1992.

BRUNER, J.S. Car la culture donne forme à l'esprit. Tradução de Yves Bonin. Paris: Eshel, 1991.

CHAUVEAU, G. et al. L'enfant apprenti lecteur. L' entrée dans le système écrit. Paris: Harmattan, 1993.

DIATKINE, R. Les jeunes enfants et les livres. La psychiatrie de l'enfant. Paris: PUF, v.XXIX, fasc.2, 1998, p. 319-337.

FIJALKOW, J. (Org.). L'entrée dans l'écrit. Toulouse: Presses Universitaires du Mirail, 1996.

FURNARI, E. A pedra no caminho. Esconde-Esconde. 4. ed. São Paulo: Ática, 1984, p. 2-3.

KATO, M. A. Estudos em alfabetização. Campinas, SP: 
Pontes; Ed. da Universidade de Juiz de Fora, 1997.

LABOV, W. La transformation du vécu à travers la syntaxe narrative. Le parler ordinaire, la langue des ghettos noirs des États-Unis. Paris: Minuit, 1978.

MASSENET, J.; JEANJEAN, M.E. Premiers pas dans l'écrit à l'école maternelle. In: CHAUVEAU, G. et al. L'enfant apprenti lecteur. L'entrée dans le système écrit. Paris: Harmattan, 1993.

MELO, L. E. Em busca de alternativas para a entrada da criança na escrita. São Paulo: Humanitas/FFLCH/ USP, 2003.

PRETI, D.; URBANO, H. (Org.). A linguagem falada culta na cidade de São Paulo. São Paulo: T. A. Queiroz; Fapesp, 1990.

REG0, R. Literatura infantil: uma nova perspectiva da alfabetização na pré-escola. São Paulo: FTD, 1990.

SCARPA, E.M. Aquisição de linguagem e aquisição da escrita: Continuidade ou ruptura? Estudos Linguísticos. In: ANAIS DE SEMINÁRIOS DO GEL, 14., Campinas, SP. Anais... Unicamp; Gel, 1987.

Recebido em: 29/09/2018 Aceito em: 17/10/2018 